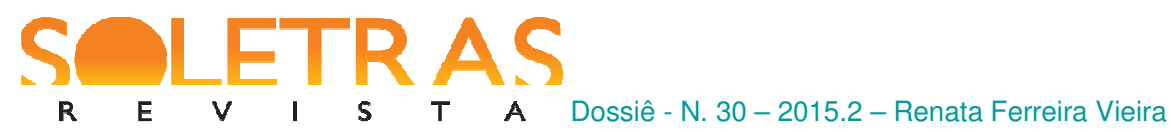

\title{
Figueiredo Pimentel e o romance $O$ aborto (1893): uma história pouco conhecida do naturalismo no Brasil
}

\author{
Renata Ferreira Vieira ${ }^{1}$ \\ Universidade do Estado do Rio de Janeiro
}

\begin{abstract}
Resumo: Nas décadas de 1890 a 1910, Figueiredo Pimentel (1869-1914) era conhecido como um dos escritores e jornalistas mais produtivos do Rio de Janeiro. Assim como outros homens de letras de sua geração, foi um polígrafo que produziu uma extensa quantidade de obras, em variados gêneros textuais: conto, poesia, crônica, teatro, folhetim, romance e literatura infantil, assumindo várias facetas em sua trajetória. Dessas facetas, duas foram parcialmente estudadas pela historiografia: a de cronista da coluna 'O Binóculo' da Gazeta de Notícias do Rio de Janeiro, que debatia os costumes cariocas na Belle Époque, e a de autor bem-sucedido do gênero de literatura infanto-juvenil. Na sua trajetória, há uma faceta que permanece pouco conhecida: o Figueiredo Pimentel autor de romances naturalistas, com que estreou na vida literária em 1893, com grande escândalo, ao lançar o romance $O$ aborto, publicado pela Livraria do Povo. Interessado na faceta naturalista do escritor, este artigo tem como objetivo apresentar um breve estudo sobre a trajetória de Figueiredo Pimentel como romancista naturalista, a partir da história da escrita, publicação e recepção do primeiro romance naturalista do autor, um best-seller que foi considerado pela crítica da época como obra pornográfica.
\end{abstract}

Palavras-chave: Figueiredo Pimentel. Naturalismo. Historiografia.

\section{Introdução}

Se o nome de Alberto Figueiredo Pimentel (1869-1914) aparece pouco nos livros de história e crítica da literatura brasileira a partir do século XX, na imprensa brasileira do final do século XIX e início do XX ele era recorrente. Pelas páginas dos jornais do período podemos conhecer sua trajetória profissional de homem de letras. Nos anos incipientes da República, entre as décadas de 1890 a 1910, Figueiredo Pimentel foi um escritor e jornalista de atuação destacada nos campos literário e jornalístico do Rio de Janeiro, praticando vários gêneros textuais, desde romance naturalista de escândalo ao conto de fadas, com participação significativa nos principais jornais do país, como cronista e redator (MENDES, 2015).

Natural de Macaé/RJ, Figueiredo Pimentel iniciou sua carreira no jornalismo no final da década de 1880, no Província do Rio, jornal da cidade de Niterói (CATHARINA, 2013). No Província do Rio, Figueiredo Pimentel apresentou, desde cedo, aptidão para escrever uma

\footnotetext{
${ }^{1}$ Graduada em Letras (Português/Literaturas) e Mestre em Teoria Literária (2015) pela Universidade do Estado do Rio de Janeiro. Este artigo é parte do resultado de pesquisa com apoio da FAPERJ. 
pluralidade de textos por meio dos seus quatro pseudônimos, entre eles: o "imoral" Albino Peixoto, autor do folhetim $O$ artigo 200, que daria origem ao bem-sucedido romance $O$ aborto; o atrevido Chico Botija, na coluna "Entre as X e as XI"; o Abelhudo, nos artigos "Para as moças"; o Tesoura, na seção "Chá de garfo"; e o Heitor Vasco, nas colunas sobre poesias (PIMENTEL, 2015, p. 87). Como só conhecemos quatro edições do jornal niteroiense - o exemplar do nº (de 15/04/1883), do acervo do Instituto Histórico e Geográfico Brasileiro (IHGB), e os três exemplares dos números 223 (de 03/12/1885), 574 (de 15/03/1888) e 656 (de 25/09/1888), pertencentes ao acervo da Biblioteca Nacional -, não sabemos com precisão as características dos pseudônimos do início da carreira do escritor.

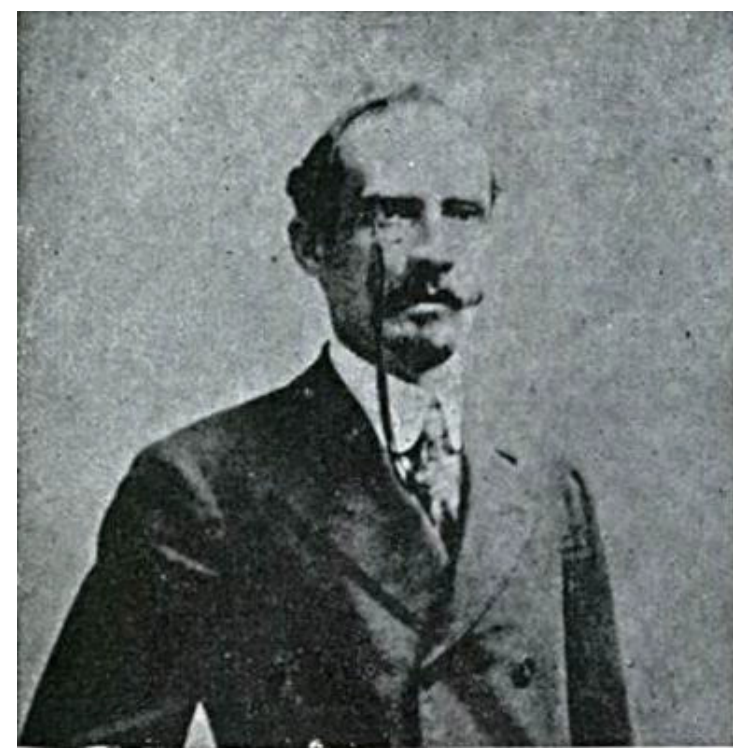

Fig.1: Alberto Figueiredo Pimentel (11/10/1869 - 05/02/1914) O País, Rio de Janeiro, 06/02/1914, p. 6.

Após a passagem pelo Província do Rio, Figueiredo Pimentel prosseguiu na carreira de escritor e jornalista em diversos jornais da capital federal. Na década de 1890, a profusão de seus trabalhos literários ganhou repercussão na opinião pública. Em 1891, no cargo de redator de $O$ País, ao lado de colegas de trabalho como o escritor e jornalista maranhense Coelho Neto (1864-1934), Figueiredo Pimentel ampliou suas relações sociais entre os homens de letras e efetuou negócios promissores num mercado editorial em expansão (A Notícia 06 a 07/02/1914, p. 1). Tendo como foco de interesse a história do escritor Figueiredo Pimentel como autor de romances naturalistas, este artigo fará uma breve incursão no "naturalismo escandaloso" do autor por meio do estudo do seu primeiro romance, $O$ aborto, publicado em 1893 pela Livraria do Povo, do livreiro-editor Pedro da Silva Quaresma (1863-1921).

\section{A publicação de $O$ aborto}

SOLETRAS - Revista do Departamento de Letras da FFP/UERJ 
Além de explorar o filão dos livros populares para fins utilitários, como os Folhetos de Música (para acompanhar as modinhas em voga) e os Manuais do Namorado (para ensinar a redação das declarações de amor), a Livraria do Povo também editava romances naturalistas de enredos escandalosos - "obscenos e lúbricos", que muitas vezes eram associados aos livros pornográficos e, por extensão, rotulados de "romances para homens" (EL FAR, 2004). Nos anúncios da livraria, os romances naturalistas eram classificados como "leitura para homens" e eram um produto comercial em demanda no comércio livreiro oitocentista. Para investir nesse segmento editorial, Pedro Quaresma aguçou o gosto por essa literatura eróticopornográfica por meio da contratação de escritores audaciosos e dispostos a despontar no gênero. Nessa combinação de fatores, em 24 de janeiro de 1893, a parceria entre Pedro Quaresma e o estreante Figueiredo Pimentel (na época com 23 anos) efetivou-se no mercado editorial, aumentando o movimento da livraria mais popular da cidade (Gazeta de Notícias, 24/01/1893, p. 2).

Durante os meses de janeiro a março de 1893, o lançamento de $O$ aborto foi precedido de uma arrojada campanha publicitária para divulgar o romance nos principais jornais do Rio de Janeiro. A divulgação pretendia despertar a curiosidade dos leitores para o "empolgante romance naturalista" editado pela Livraria do Povo. Em poucas palavras, o editor Pedro Quaresma criou uma grande expectativa em relação ao romance e, por extensão, ao jovem escritor Figueiredo Pimentel. O editor contava atrair leitores com o título sensacionalista e a filiação à estética naturalista, associada ao sexo e ao escândalo (MENDES, 2006).

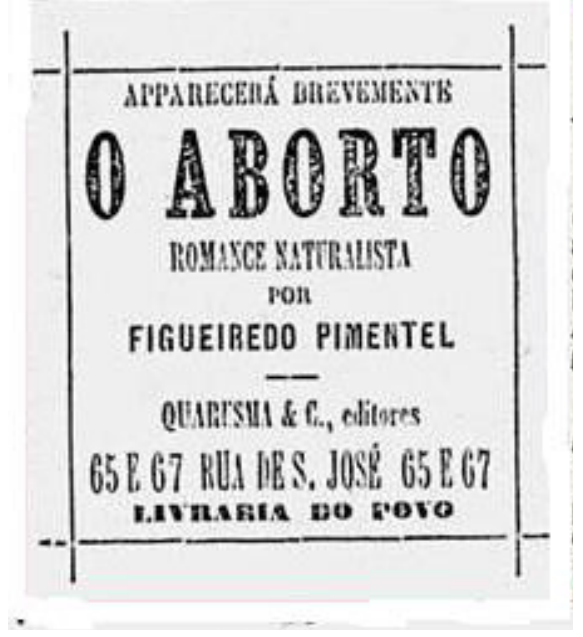

Fig. 2: $O$ País - Rio de Janeiro, 29/01/1893, p. 8 Aparecerá brevemente $O$ aborto, romance naturalista por Figueiredo Pimentel 
As expectativas sobre o lançamento de $O$ aborto chegaram ao fim em 20 de março de 1893, com a nota da Gazeta de Notícias sobre o início das vendas do romance. Segundo o jornal, a obra era "realista", expressando a oscilação entre os termos "naturalista" e "realista" no período: “ $O$ aborto está publicado e será posto à venda, quinta-feira [23/03/1893], este soberbo romance realista, do eminente escritor Figueiredo Pimentel, redator de $O$ País, 1 belo volume por $2 \$ 000$ [dois mil réis]" (p. 4). Em 23 de março de 1893, foi a vez de O País anunciar a disponibilidade do romance na Livraria do Povo e nas mais conhecidas livrarias da capital federal, como a Laemmert e a Garnier. A nota do jornal destacou a linguagem direta do romance naturalista de Figueiredo Pimentel, sugerindo que a obra continha "pitadas de escândalos", como as dos escritores naturalistas franceses Emile Zola (1840-1902) e Paul Bonnetain (1858-1899), autor de Charlots'amuse (1883), um romance sobre a masturbação:

Já está publicado $O$ aborto, romance naturalista de Figueiredo Pimentel, há muito anunciado. Escrito sem rebuços de linguagem, consoante a maneira de Zola, Bonnetain e outros mestres do naturalismo, $O$ aborto promete um grande sucesso de livraria, tendo todos os elementos para agradar ao público amante do gênero. Apensos ao romance seguem-se alguns contos e fantasias do mesmo autor. O volume, assim formado, consta de 270 páginas e é bem impresso nas oficinas da Companhia Impressora, por conta dos editores Quaresma \& C. (O País 23/03/1893, p. 2).

A promessa de $O$ aborto ser um grande sucesso de vendas virou realidade em 26 de março de 1893. Vários jornais da cidade anunciaram o êxito da Livraria do Povo e exaltaram o fenômeno de venda do romance com poucos dias de circulação:

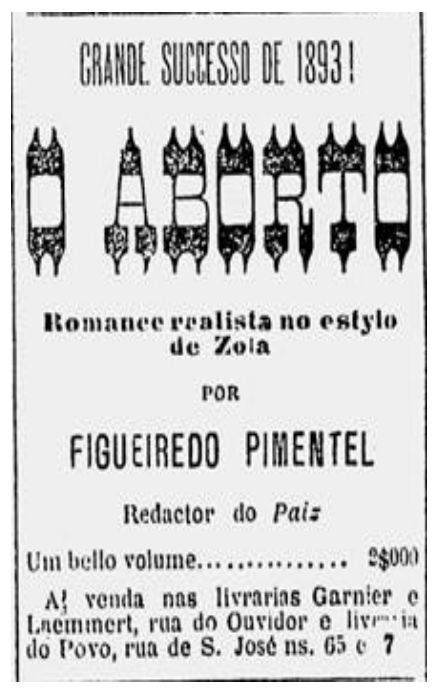

Fig. 3: Diário de Notícias/RJ, 26 de março de 1893, p. 3.

Grande sucesso de 1893! O aborto, romance realista no estilo de Zola, por Figueiredo Pimentel 
Para a imprensa, $O$ aborto foi um acontecimento literário que impressionou a todos; para Pedro Quaresma, foi um negócio bem-sucedido. A primeira edição do romance vendeu mais de seis mil exemplares, o que elevou o faturamento da Livraria do Povo (EL FAR, 2004). Os recursos usados por Pedro Quaresma para divulgar $O$ aborto, como a disponibilidade do romance em vários pontos de venda, a prestação de serviços de caixeirosviajantes para entregar o livro em localidades distantes, o título sensacionalista e, principalmente, o baixo valor de dois mil réis do livro, ajudaram a despertar o interesse do público leitor. O romance, além de ter sido um best-seller, foi a obra que apresentou Figueiredo Pimentel ao campo literário como autor de romances naturalistas. A obra "alvoroçou" a crítica e a sociedade por meio do "enredo escandaloso" que ultrapassava as próprias transgressões dos romances atribuídos ao naturalismo. O empreendedorismo de Quaresma e a "sensação" do primeiro romance naturalista de Figueiredo Pimentel foram assunto por muitos meses na imprensa carioca, que divulgava (e reconhecia) o caráter extraordinário de $O$ aborto no mercado editorial do final do século XIX.

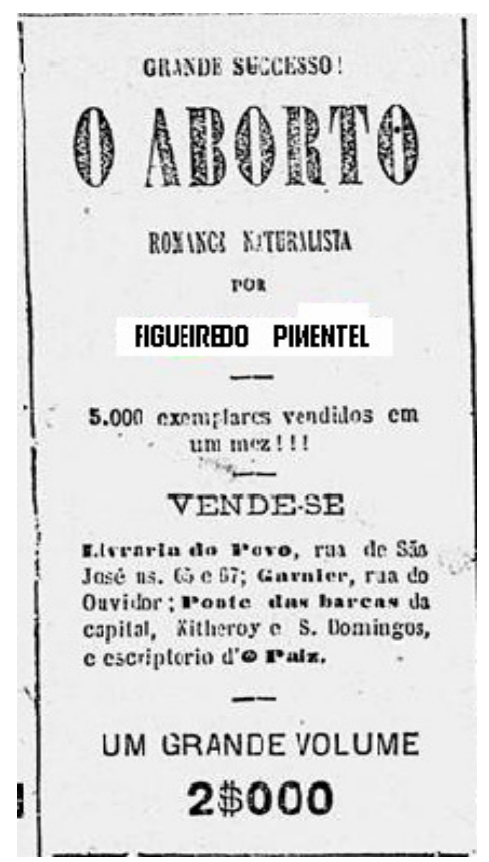

Fig. 4: $O$ País/RJ, 29 de abril de 1893, p. 5 5.000 exemplares vendidos em um mês!!!

Antes de ser editado em volume, $O$ aborto tinha sido publicado em folhetins pelo Província do Rio, em 1889, sob o título de $O$ artigo 200, em referência ao artigo do Código Penal do Império do Brasil que criminalizava o aborto. O romance era assinado por um dos pseudônimos de Figueiredo Pimentel - Albino Peixoto. Durante a publicação do folhetim, muito leitores de Niterói reclamaram contra o caráter pornográfico da história, obrigando o 
proprietário do jornal, Joaquim Ferreira Guimarães, a suspender o folhetim antes do capítulo final (PIMENTEL, 2015).

A história do romance, supostamente verídica, narrava a vida banal de Maria Rodrigues (Maricota), uma moça de família pequeno-burguesa, que após a falência dos negócios do pai, muda-se de Rio Bonito, com a família, para viver em Niterói do final do século XIX. Explicitamente filiado ao naturalismo, o romance descrevia, de modo franco, os encontros sexuais de Maricota com o primo Mário, que resultaram numa gravidez indesejada e interrompida por um aborto. O título escandaloso do romance e as ousadas descrições das "cenas obscenas" provocaram diversas manifestações dos críticos, que ficaram impactados com o "tom picante" da narrativa em nome da estética naturalista.

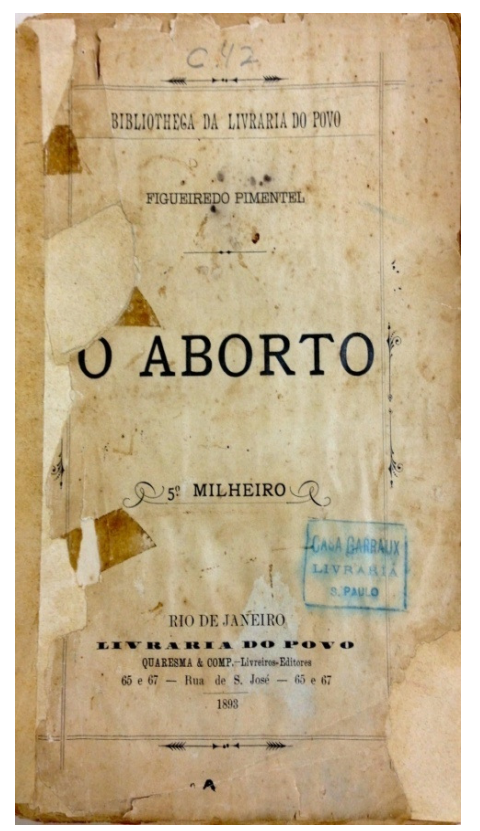

Fig. 5: Folha de rosto da $1^{\mathrm{a}}$ edição de $O$ aborto Exemplar da Biblioteca César Lattes (UNICAMP)

Na imprensa, os críticos foram unânimes em afirmar que o romance de estreia de Figueiredo Pimentel não atendia às regras do naturalismo sério, desviando-se para o aspecto pornográfico e "sensacionalista" da estética. Apesar do consenso da recepção crítica, a obra obteve 'apoio literário' de alguns críticos que, aparentemente, condenavam os recursos ficcionais da pornografia, mas, nas entrelinhas, faziam reclame ao romance.

\section{Alvoroço de crítica e de público}

Com repercussão fenomenal na imprensa, $O$ aborto foi um dos livros mais comentados do ano de 1893 (A Palavra, Pará, 15/09/1895, p. 3). Para mantê-lo "vivo" na memória dos 
leitores e da crítica, Figueiredo Pimentel, no prefácio do romance, solicitou aos críticos que lhe enviassem as resenhas sobre $O$ aborto para estimular os debates sobre o "livro escandaloso" e para divulgar o próprio nome no campo literário: “Àqueles que escreverem sobre este livro, peço que me enviem um exemplar do periódico, com o endereço: Figueiredo Pimentel, Redação d'O País, Rua do Ouvidor no 63 - 65, Rio de Janeiro" (PIMENTEL, 2015, p. 17).

A solicitação do escritor foi atendida, pois os críticos colocaram $O$ aborto na "ordem do dia" das apreciações da imprensa. De modo geral, a crítica entendeu o romance como um produto pornográfico destinado a provocar escândalos. Dessas apreciações, as resenhas do escritor Carlos Magalhães de Azeredo (1872-1963), publicadas na Gazeta de Notícias em meados de 1893, foram exemplares como repúdio e condenação da "obra, linguagem e estilo de Figueiredo Pimentel" (Gazeta de Notícias RJ, 19/06/1893, p. 1).

Apesar do consenso condenatório ao caráter pornográfico do romance, havia também a ‘crítica de apoio literário' que promovia o livro sob a estratégia de divulgá-lo por meio de "censuras e reprovações" ao gênero obsceno. Aqui cabe a resenha de Coelho Neto, publicada em $O$ País logo depois do aparecimento da obra. Membro destacado do grupo de escritores boêmios de 1880, Coelho Neto assinava literatura pornográfica com o pseudônimo de Caliban. Conhecido escritor profissional, Coelho Neto escreveu quase todos os gêneros textuais. Muitos escritores escreviam textos pornográficos com o objetivo de iniciar a carreira literária. Alguns eram levados pelas privações econômicas. Desde o século XVIII, a "literatura clandestina" era garantia de sucesso de público e era atraente, em algum momento da vida, aos escritores mais ou menos reconhecidos (GOULEMOT, 2000, p. 48).

A provocação de Figueiredo Pimentel às "penas dos críticos” foi um ótimo recurso para manter a divulgação de $O$ aborto. A iniciativa do escritor, aliada ao "tino comercial" do livreiro-editor Pedro Quaresma, não deixou o romance ser ignorado pela crítica especializada dos principais jornais. Dentre a "enxurrada de apreciações" enviadas à redação de $O$ País, Figueiredo Pimentel reconheceu - em 1896, no prefácio do seu quarto romance, O terror dos maridos - que a resenha de Coelho Neto foi de grande valia, colaborando para consolidar a parceria e o apoio entre os homens de letras, como também evocar a opinião pública sobre o "naturalismo pornográfico" produzido no Brasil:

Coelho Neto, o brilhante estilista, que era nessa época meu colega na redação d' $O$ País, escreveu sobre ele [O aborto], a 26 de março [1893], um artigo humorístico, assinado Caliban, que lhe foi excelente reclame. Não entenderam, porém. Pensaram que se tratava de uma sova mestra descompostura em termos. A imprensa inteira acompanhou-o. Creio que não houve um só jornal no Brasil que silenciasse em absoluto sobre o meu livro. 
Jamais obra alguma literária, despretensiosa como essa, analisada. (PIMENTEL, 1896, p. 02-03).

Na apreciação de $O$ aborto publicada pelo $O$ País em 26 de março de 1893, Coelho Neto comentou que o livro, de "concepção arrojada e fatura audaciosa, escrito por Figueiredo Pimentel [era] um fenômeno literário, um sucesso de livraria" ( $O$ País, 26/03/1893, p. 1). Em tom jocoso e sem mencionar o título do romance em respeito à "tradição de castidade" da coluna, Coelho Neto elaborou uma ‘crítica de apoio literário' que repudiou os “meios terríveis de que se serviu o autor para desenvolver as ações do romance" ( $O$ País, 26/03/1893, p.1) e, simultaneamente, incitou a curiosidade do público pela sensual Maricota:

$\mathrm{O} \mathrm{AB} \ldots$

(por Figueiredo Pimentel)

[...] Maricota é uma lânguida que faz esquecer todas as mulheres de Lesbos, Safo inclusive. Seus sonhos são produzidos pelo suco do hipomanes [líquido mucoso expelido pela égua no período de cio], o seu pensamento sempre lúbrico; deixa-se levar unicamente, exclusivamente pelo instinto brutal da sua mocidade - é um tipo violenta de nevrótica, talvez não me exprima bem, não é nevrótica, é de... sei lá! de bacante, compreendem? Se não compreendem, a culpa não é minha, bem veem que nesta coluna, que tem uma tradição de castidade, não ficava bem a definição do tipo de Maricota. Só lhes posso dizer que é um tipo às direitas. Caliban (O País, 26/03/1893, p. 1).

$\mathrm{Na}$ opinião de Coelho Neto, o comportamento lascivo de Maricota fazia esquecer a sensualidade delicada e sofisticada da poetisa grega Safo e das suas discípulas, as mulheres de Lesbos. Objetivamente, o crítico alertava aos pudicos leitores da sua coluna sobre a impudência de $O$ aborto. As "inspirações" do romance provinham do deus romano Baco divindade do vinho e das orgias. Apesar do aviso, a advertência do crítico não indicava reprovação ao gênero pornográfico, porque a prevenção de $O$ aborto era, exclusivamente, para os leitores de "tradição de castidade", acostumados à poética lírica e idealista dos franceses Bernardin de Saint-Pierre (1737-1814) e Alphonse de Lamartine (1790-1869) e do italiano Francesco Petrarca (1304-1374), sem restrições aos demais leitores interessados nas “obras de sabor picante e de páginas perturbadoras".

Olhos puríssimos, espíritos imaculados, não é para vós esse livro. Deixai que o leiam os que não têm preconceitos, os que não têm escrúpulos, esses hão de achar nele um sabor picante que procuram nas memórias do Marquês de Sade, de Gilles de Rais, nas memórias de Richelieu, nos contos da rainha de Navarra, no Eriticon de Beranger ou no livro do amor dos brahmas [obras classificadas como pornográficas e catalogadas no gênero "leitura para homens", segundo os anúncios das livrarias da época]. Vós outros, habituados às doçuras de Bernardin de Saint Pierre e de Lamartine e aos versos tristes de Petrarca, deixai que as traças devastem esse livro perigoso, que é silício [ácido] para a carne frágil (O País, 26/03/1893, p. 1). 
Para Coelho Neto, a história de Maricota pertencia à categoria dos "livros perigosos", frequentemente associados aos "romances para homens" (EL FAR, 2004) e às "obras pornográficas com requinte de crueldade", como as memórias do Marquês de Sade e Gilles de Rais - com histórias sobre estupros, incestos, parricídios e enredos terríveis de tortura e assassinato. Embora a comparação de $O$ aborto com os 'textos macabros' da literatura pornográfica nos pareça exagerada nos dias atuais, para o imaginário dos leitores do século XIX, o enredo de $O$ aborto era tão violento e criminoso quanto às memórias de Sade ou Gilles de Rais. Nesse sentido, podemos depreender o impacto do escândalo causado pelo romance de estreia de Figueiredo Pimentel.

O perigo de $O$ aborto justificava-se pela audácia do enredo, que descrevia (sem omissões) os pormenores da vida sexual da jovem Maricota, em desafio às convenções morais da sociedade niteroiense. Com o argumento naturalista de que o romance seguia a forma do estudo científico sobre "um fato ocorrido em Niterói” (PIMENTEL, 2015, p. 24), Figueiredo Pimentel não se esquivou de detalhar situações íntimas (e embaraçosas) da trajetória medíocre de Maricota e sua família desde a cidade de Rio Bonito à Praia Grande - "a terra das oportunidades" (PIMENTEL, 2015, p. 35-36), como também da "hipócrita burguesia e cheia de preconceitos" do bairro de Icaraí (PIMENTEL, 2015, p. 21).

Se a apreciação crítica de Coelho Neto divulgou subliminarmente $O$ aborto, a de Carlos Magalhães de Azeredo, da Gazeta de Notícias, condenou-o severamente, associando a obra à literatura pornográfica. Horrorizado com a repercussão do livro, Magalhães de Azeredo quase três meses após a publicação da obra - pediu a palavra para criticar a excepcional venda do "romance bárbaro" que maculou o ofício dos verdadeiros escritores das belas-letras. Para expressar sua indignação, o crítico escreveu uma longa resenha "contra $O$ aborto" e contra a conivência do escritor com os interesses do mercado livreiro:

A razão por que me ocupo de $O$ aborto, quando semelhante novela está por sua natureza fora das cogitações de um artista honesto e de um escritor que se preza, é, saibam-no todos os que lerem estas linhas (com certeza terão lido o Aborto), o fenomenal sucesso de livraria que alcançou esse digno êmulo das Malaguetas, dos Camarões apimentados, o outras que tais leituras clandestinas. Pouco depois de sair a lume o romance, folhei-o distraidamente em uma livraria, e logo depois o pus de parte, porque, depois de dez ou doze páginas, achei que lera de sobra.

Mas, há dias, de relance, vejo num exemplar de $O$ aborto, com a tinta de impressão ainda fresca: $6^{\circ}$ milheiro! Decidi-me então a comprá-lo, a trazê-lo para casa no intuito de descobrir que qualidades justificavam êxito tão assombroso num livro assombrosamente ruim. Confesso que não tive extrema surpresa; não sou otimista, nem ingênuo demais, e já esperava mais ou menos, o que vi; mas ainda assim, não esperava tanto. (...) Este livro não é mais que um objeto de comércio, com que o editor vos explora, fazendo- 
vos pagar o imposto dos vossos vícios e da vossa depravação moral... (Gazeta de Notícias RJ, 19/06/1893, p. 1).

Magalhães de Azeredo não escondia o repúdio ao romance de estreia de Figueiredo Pimentel. Para o crítico, a literatura do escritor "saía do terreno das letras propriamente ditas, para cair no domínio da pseudo-literatura, industrial e pornográfica" (Gazeta de Notícias RJ, 19/06/1893, p. 1). Magalhães de Azeredo compreendia que a produção de "romances comerciais" em grande escala "rebaixava a arte literária" e a crítica profissional - instituição que tinha a missão de "vigiar as fronteiras da Arte, ameaçadas por invasões de bárbaros" (Gazeta de Notícias RJ, 19/06/1893, p.1). Considerando-se como um dos "missionários da Arte", Magalhães de Azeredo viu-se na obrigação de condenar publicamente $O$ aborto, romance que, para ele, rejeitava as regras estéticas do naturalismo para filiar-se ao "ultranaturalismo" - termo usado pelo crítico para denominar a pornografia (Gazeta de Notícias RJ, 19/06/1893, p. 1). Magalhães de Azeredo entendia a escrita pornográfica como um "sacrilégio à verdadeira literatura" (Gazeta de Notícias RJ, 19/06/1893, p. 1). Para ele, "autores comerciais" não tinham seriedade e romances como O aborto e outros tantos manuais vendidos pela Livraria do Povo não eram literatura.

Diante do fato de que $O$ aborto não foi ignorado pela crítica e nem pelo público, Magalhães de Azeredo retornou às folhas da Gazeta de Notícias, em 03 de julho de 1893, para erguer outra vez sua voz contra o romance de Figueiredo Pimentel: "se $O$ aborto vivesse obscuramente dois dias, eu não me ocuparia dele; mas o seu êxito imerecido justifica o meu rigor" (Gazeta de Notícias RJ, 03/07/1893, p. 1). Para o crítico, o naturalismo como observação científica sobre "temas dignos" da experiência humana era importante, mas os estudos sobre os "quadros de imoralidades repugnantes" recolhidos no cotidiano ordinário eram deploráveis, porque partiam da "pior parte do gênio naturalista" - a inclinação irresistível para as pinturas pornográficas (Gazeta de Notícias RJ, 03/07/1893, p. 1).

$\mathrm{Na}$ concepção de Magalhães de Azeredo, "naturalismo bom” era aquele regido pelo "realismo casto, aristocrático e limpo", oposto ao "realismo purulento e fétido, que em tantas páginas chega a enojar a humanidade" (Gazeta de Notícias RJ, 19/06/1893, p. 1). Segundo a reflexão do crítico, $O$ aborto estava na segunda categoria de realismo, portanto no "naturalismo ruim", que escandalizava os "devotos das letras nacionais" por meio de um texto impregnado de obscenidades e carente de "uma linguagem vernácula, um estilo pessoal e quadros descritivos de consumada perfeição" (Gazeta de Notícias RJ, 19/06/1893, p. 1). Possuidor de tantos defeitos, $O$ aborto incomodou o crítico, especialmente, nas cenas sobre o 
“comportamento prostituído" de Maricota. Para ele, a audácia da protagonista em "procurar o primo no quarto" não podia ser explicada pela fisiologia nem pela psicologia:

Vestida apenas com uma camisa de linho rendada na gola, mostrando o colo, os seios túrgidos, as pernas nuas quase até os joelhos, deixando entrever as formas opulentas, a barriga meio empinada, os quadris largos, a carne exuberante, Maricota Rodrigues parecia antes uma estátua. Mário sentiu-se mal, com febre, atordoado, ao mesmo tempo deslumbrado pela beleza da moça. Invadiu-lhe de súbito um grande desejo de cópula, preso de uma potência desenfreada, com o pênis teso, ereto, repuxando a colcha. Era tarde. Todos dormiam em casa. Tinha em seu quarto uma mulher bonita, apetitosa, que o amava loucamente, a ponto de vir procurá-lo, desatinada. E fazia esforços para não se erguer rapidamente, e sem que ela pudesse evitar, agarrá-la, atirá-la ao chão, num ímpeto brutal, selvagem, despedaçar-lhe a camisa, e gozá-la nos espasmos do prazer delirante.

Conteve-se, entretanto. Então a rapariga, sempre serena, apoiando a mão direita no colchão, inclinou-se, fazendo saltar os seios rijos, turgentes, pela gola larga da camisa, e deu-lhe um beijo na testa. Não pôde mais. Um tremor convulso abalou-lhe o corpo inteiro, arrepiando-o todo, como um frisson de febre, lambendo-lhe finalmente a epiderme, numa carícia áspera e suave, de dor e prazer, ao longo da espinha dorsal. Sentiu assim como se alguém lhe houvesse, com férrea manopla, dado um grande murro sobre o crânio. Ouviu um ruído subterrâneo, prolongado. Zuniam-lhe os ouvidos. Os olhos viam pequeninas fagulhas, chispando rubras em fundo trevoso. Em nada pensou. Desvairado, alucinado, louco, agarrou-a pela cintura, arremessou-a brutalmente sobre a cama, forçou-lhe as pernas resistentes, separando-as, e, deitado por cima, beijando-a, mordendo-a, enterrando-lhe a língua na boca até quase a garganta, abraçando-a com frenesi, num longo e estreitado aperto, gozou-a uma vez... duas vezes... três vezes... [...] Ela também gritou, gritou alto - ouvia ainda: 'Mário! Mário! Não! Não! Você me mata! Ai! Ai!' (PIMENTEL, 2015, p. 66-69).

A cena de Maricota indo, decididamente, ao quarto do primo, impactou os críticos. Não houve apreciação crítica que não abordasse, com espanto, a audácia da protagonista de $O$ aborto e a "crueza das ações" descritas na história, típicas do gênero pornográfico. Na resenha de Coelho Neto, o crítico chamou atenção para "tais ações indecorosas" desenvolvidas no livro:

Há cenas que fariam corar o sol se o astro tivesse a fortuna ou a desgraça de conhecer as letras do alfabeto - a linguagem é de uma espontaneidade violenta - não há um circunlóquio, não há uma frase velada - as coisas são ditas claramente, sem rebuço, com todos os fff e rrr, com todos os rrr principalmente (O País, 26/03/1893, p. 1).

O “escândalo" causado pelo $O$ aborto não era inédito. Romances como A carne (1888), de Júlio Ribeiro (1845-1890), e O primo Basílio (1878), do escritor português Eça de Queirós (1845-1900) - sucesso de leitura no Brasil -, já haviam ficcionalizado a atração da mulher pelo primo distante ou pelo homem que passa a conviver na mesma casa, sem o vínculo do casamento. $\mathrm{O}$ escândalo causado pelo $O$ aborto foi o ineditismo da descrição do órgão genital 
masculino durante o ato sexual. Romances naturalistas brasileiros, como $O$ cortiço (1890), de Aluísio Azevedo (1857-1913), e A carne não ousaram tanto nas descrições das cenas de sexo e nem se afastaram de uma linguagem naturalista apurada para narrar "as intimidades das alcovas".

A disposição de Figueiredo Pimentel em descrever "cenas picantes" em $O$ aborto configurou o dialogismo entre o romance naturalista e a pornografia, dois discursos que criticavam as convenções sociais ditadas pela ordem estabelecida, desafiando a hierarquia tradicional (JACOB, 1999). Considerando a pornografia na literatura a partir da perspectiva histórica do século XIX, podemos observar que a aproximação do naturalismo às obras pornográficas efetivava-se no protagonismo do corpo humano nos textos produzidos e na propagação do pensamento materialista, que mecanizava e despia os corpos, vistos como simples matéria em movimento (JACOB, 1999). Desse modo, o naturalismo e a pornografia partiam da concepção de que a natureza essencial do homem era o seu corpo e todas as implicações ligadas a ele, especialmente o desejo sexual.

Vivenciando o imaginário materialista do século XIX, Figueiredo Pimentel elaborou um romance naturalista de escrita atrevida, que não se esquivou da associação entre a ficção naturalista e a literatura pornográfica. $\mathrm{O}$ escritor reconheceu a similaridade entre os gêneros e alegou não se importar que o chamassem de autor pornográfico, conforme sua declaração no prefácio de $O$ aborto:

Agora, pouco me importa que ele [o romance] seja pechado de pornográfico, imoral, bandalho. Para mim, será até uma honra e uma glória: Emilio Zola, Eça de Queiroz, Aluísio Azevedo, Pardal Mallet - todos naturalistas - para este público besta, que lê os Serões do convento e vê operetas, são também pornográficos, imorais e bandalhos (PIMENTEL, 2015, p. 21).

Figueiredo Pimentel notou que era comum chamar os romancistas naturalistas de pornográficos. Os livros naturalistas baseados em estudo sério e científico eram confundidos com as "obras de fancaria", como o clássico Os serões do convento, que foi um fenômeno de vendas, sendo "um dos livros pornográficos de maior circulação no Brasil de Oitocentos" (EL FAR, 2004, p. 52). Independente das distinções entre naturalismo e pornografia por parte dos críticos que insistiam em evocar o prestígio da ciência para a estética, os romances naturalistas eram lidos e apropriados como obras do gênero pornográfico, com textos capazes de provocar excitação sexual no leitor (ou leitora) por meio de uma linguagem grosseira ou, senão, obscena. Embora o enredo naturalista explorasse os corpos humanos e a sexualidade de um ponto de vista científico, o romance era apropriado pelos livreiros e leitores comuns (e 


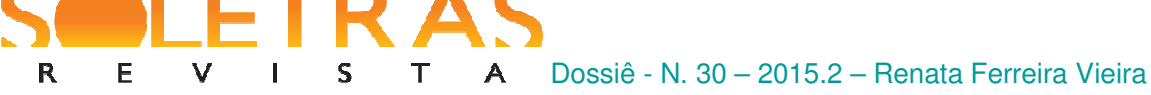

pela crítica especializada) como uma literatura destinada aos "divertimentos do corpo ou às folganças da carne" (GOULEMOT, 2000, p. 31-32).

\section{Considerações Finais}

A fama de "escritor imoral" de Figueiredo Pimentel permaneceu por muito tempo na sua carreira de escritor, pois " $O$ aborto fez com que fosse criado ao redor do seu nome literário um cordão vigilante de sanidade moral pelos pais cautelosos e pela crítica" ( $A$ Notícia, 28 a 29/08/1895, p. 2). Ainda que os romances que sucederam ao $O$ aborto não trouxessem "cenas picantes" - como Um canalha (1895), Suicida! (1895) e O terror dos maridos (1896) -, para a recepção crítica, os romances naturalistas de Figueiredo Pimentel eram "sinônimos de escândalos" (PIMENTEL, 1896, p. 06). Em O aborto, o escândalo foi a disposição do romance para "escancarar aos olhos da realidade" (A Noite, 06/02/1914, p. 1) as experiências transgressoras da sexualidade feminina.

Para o imaginário de leitura da época, $O$ aborto era um romance naturalista indecente que corrompia os valores morais, pois dissociava a imagem da mulher e seu corpo do sexo reprodutivo. Na história, Maricota - apesar do seu fim trágico, vítima de um aborto que encerrou sua breve vida de dezessete anos, vividos com transgressão e destemor simbolizava os desejos femininos que passavam longe da maternidade e caminhavam para a realização de uma vida sexual não reprimida. O romance de estreia de Figueiredo Pimentel foi obra ousada que colaborou para fomentar reflexões sobre a vigilância da sexualidade feminina, atada aos rigores da sociedade burguesa e patriarcal. Tal sociedade condenava as mulheres que rompiam as convenções sociais para viverem sua vida sexual, porém absolvia os homens - seus parceiros de "violação moral”, sem nenhuma punição ou constrangimento.

Com $O$ aborto, Figueiredo Pimentel deu o ponto de partida para sua trajetória de romancista naturalista, sem temer críticas e censuras ao "escrever livros sem peias", que impactaram a sociedade e marcaram a história do naturalismo no Brasil.

\section{Referências bibliográficas:}

CATHARINA, Pedro Paulo Garcia Ferreira. De "O artigo 200" a "O aborto": trajetória de um romance naturalista. Letras, Santa Maria, v. 23, n. 47, p. 37-58, jul./dez. 2013.

EL FAR, Alessandra. Páginas de sensação: Literatura popular e pornográfica no Rio de Janeiro (1870-1924). São Paulo: Cia. das Letras, 2004. 
GOULEMOT, Jean-Marie. Esses livros que se leem com uma só mão: leitura e leitores de livros pornográficos no século XVIII. São Paulo: Discurso Editorial, 2000.

JACOB, Margaret. O mundo materialista da pornografia. In: HUNT, Lynn (Org.). A invenção da pornografia: obscenidade e as origens da modernidade. São Paulo: Editora Hedra, 1999. p. 169-215.

MENDES, Leonardo. Sordid literature: naturalism and sexuality in Brazil. Excavatio International Review for Multidisciplinary Approaches and Comparative Studies related to Emile Zola and his Time, Canadá, v. 21, p. 48-62, 2006.

O Zola da Praia Grande: Figueiredo Pimentel e o naturalismo. In: PIMENTEL, Figueiredo. $O$ aborto. Estabelecimento do texto e organização de Leonardo Mendes e Pedro Paulo Garcia Ferreira Catharina. Rio de Janeiro: 7Letras, 2015 [1893], p. 7-14.

PIMENTEL, Figueiredo. $O$ aborto. Estabelecimento do texto e organização de Leonardo Mendes e Pedro Paulo Garcia Ferreira Catharina. Rio de Janeiro: 7Letras, 2015 [1893].

1896.

O terror dos maridos: cenas da alta sociedade. Rio de Janeiro: Livraria J. R. Santos,

\section{Periódicos consultados:}

Hemeroteca Digital Brasileira; Fundação Biblioteca Nacional: http://hemerotecadigital.bn.br/ A Noite, Rio de Janeiro, 06/02/1914, p. 1.

A Notícia, Rio de Janeiro, 28 a 29/08/1895, p. 2.

A Notícia, Rio de Janeiro, 06 a 07/02/1914, p. 1.

A Palavra, Pará, 15/09/1895, p. 3.

Diário de Notícias, Rio de Janeiro, 26/03/1893, p. 3.

Gazeta de Notícias, Rio de Janeiro, 24/01/1893, p. 2.

Gazeta de Notícias, Rio de Janeiro, 20/03/1893, p. 4.

Gazeta de Notícias, Rio de Janeiro, 26/03/1893, p. 8.

Gazeta de Notícias, Rio de Janeiro, 19/06/1893, p. 1.

Gazeta de Notícias, Rio de Janeiro, 03/07/1893, p. 1.

O País, Rio de Janeiro, 29/01/1893, p. 8.

O País, Rio de Janeiro, 23/03/1893, p. 2.

O País, Rio de Janeiro, 26/03/1893, p. 1.

O País, Rio de Janeiro, 29/04/1893, p. 5.

O País, Rio de Janeiro, 06/02/1914, p. 6.

Figueiredo Pimentel and the novel $O$ aborto (1893): a little known story of Brazilian naturalism

Abstract: In the decades of 1890 at 1910, Figueiredo Pimentel (1869-1914) was known as one of the most productive writers and journalists in Rio de Janeiro. Like other men of letters 
of his generation, Figueiredo Pimentel was a polygraph that practiced various textual genres: short story, poetry, chronicle, drama, feuilleton, novel and children literature, adopting several facets in his career. Two have been partially studied by historiography: the chronicler of the 'O Binóculo' column of the Gazeta de Notícias do Rio de Janeiro, that debated the customs in the Belle Époque, and the successful author of children literature. In his path there is a facet that remains little known: Figueiredo Pimentel the author of naturalist novels, with which he debuted in literary life in 1893, with great scandal, by launching the novel $O$ aborto, published by Livraria do Povo. Interested in naturalist facet of the writer, this article aims to present a brief study of the trajectory of Figueiredo Pimentel as a naturalist novelist, focusing on the history of writing, publication and reception of his first naturalist novel, a best-seller that was considered by critics of the time as a pornographic work.

Keywords: Figueiredo Pimentel. Naturalism. Historiography.

Recebido em: 7 de setembro de 2015 .

Aprovado em: 20 de dezembro de 2015 . 